\title{
AN EMPIRICAL INDEX OF SEASONAL VARIATION OF INTENSE PRECIPITATION OVER LARGE AREAS
}

\author{
R. W. SCHLOEMER \\ U. S. Weather Bureau, Washington, D. C. \\ [Manuscript received May 16, 1955; revised November 10, 1955]
}

\begin{abstract}
Adequate design and sound operational procedures for levees, spillways, and multiple-purpose reservoirs require a knowledge of seasonal variation of precipitation of high intensity as well as soil infiltration capacities, antecedent rainfall, and snow melt. The problem of seasonal variation is approached by indirect methods since there is an inadequacy of data on large storms. A technique of areal smoothing is introduced and used to overcome lack of suitable areal distribution of large storms studied in detail. A set of bi-weekly charts is developed giving approximately equal likelihood of occurrence of high rates of rainfall over areas of 20,000 square miles in 72 hours.
\end{abstract}

\section{INTRODUCTION}

The role of the hydrometeorologist in engineering design is to provide the engineer with as much meteorological information as possible which may contribute to safe and economical construction of a particular structure. In the design of levees, spillways, or multiple-purpose reservoirs the meteorological problem is not alone one of amounts of precipitation but, because of varying infiltration capacities of the soil, antecedent rainfall, snow melt, and other variables, it is also a problem of seasonal variations of precipitation of great intensity. To date the storm study program of the Corps of Engineers, Department of the Army [1] has encompassed about 600 storms of intense precipitation. This program is designed to study the depth-duration-area characteristics of major storms in the United States. Results are tabulated and published as pertinent data sheets as illustrated by figure 1. As yet, too few fall, winter, and spring storms have been studied to provide a suitable approximation to the true seasonal characteristics of large-area precipitation. Until such time that the meteorologist can set down a theoretical solution to the problem of precipitation, its causes and its seasonal characteristics, or until such time that an adequate portrayal of precipitation distributions can be presented by synoptic climatological means, approximations of the desired information will have to be made by engineering techniques. This paper presents one such engineering technique that serves as a partial solution to the problem of seasonal variation of intense precipitation over large areas.

J. B. Kincer [2] plotted the monthly State averages of precipitation for the 55-year period 1886-1940 and tabulated by States the percentages of years having averages of $0-.99,1.00-1.99,2.00-2.99,3.00-3.99,4.00-4.99$, and
$5.00+$ inches. In the interest of utility, S. S. Visher [3] plotted some of the categories tabulated by Kincer and ventured to draw isolines on the charts to make the data easier to grasp. Under the direction of W. F. McDonald an activity of the Works Projects Administration reviewed and tabulated daily precipitation records from all stations operated by the Weather Bureau (see fig. 2) during the 30-year period, 1906-1935. These 24-hour amounts were summarized within standard weekly intervals beginning on January 1. The 29th of February once every four years and the last day of each year were included in the encompassing week, but the values for such periods were proportionally adjusted to a 7-day basis. Individual station weekly averages were plotted on charts and smoothed, as were average daily intensities. These charts are in published form [4] and are also printed on the back of The Daily Weather Map periodically. These data were also summarized and tabulated as weekly averages over each of the climatological divisions of the United States. Although most of the divisions are about 20,000 square miles in area their size varies considerably as can be seen in figure 3.

The Hydrometeorological Section of the Weather Bureau has from time to time studied portions of the seasonal variation of precioitation over particular drainage areas [5] iand the seasonal variation of precipitation over small areas [6]. The data tabulated for climatological divisions serve as a basis for a generalized evaluation of the seasonal variation of precipitation over moderately large areas. It would be preferable to study seasonal variation of 72-hour rainfall directly. Since such data are not available the assumption is made that seasonal variation of weekly amounts and 72-hour amounts are reasonably consistent. 


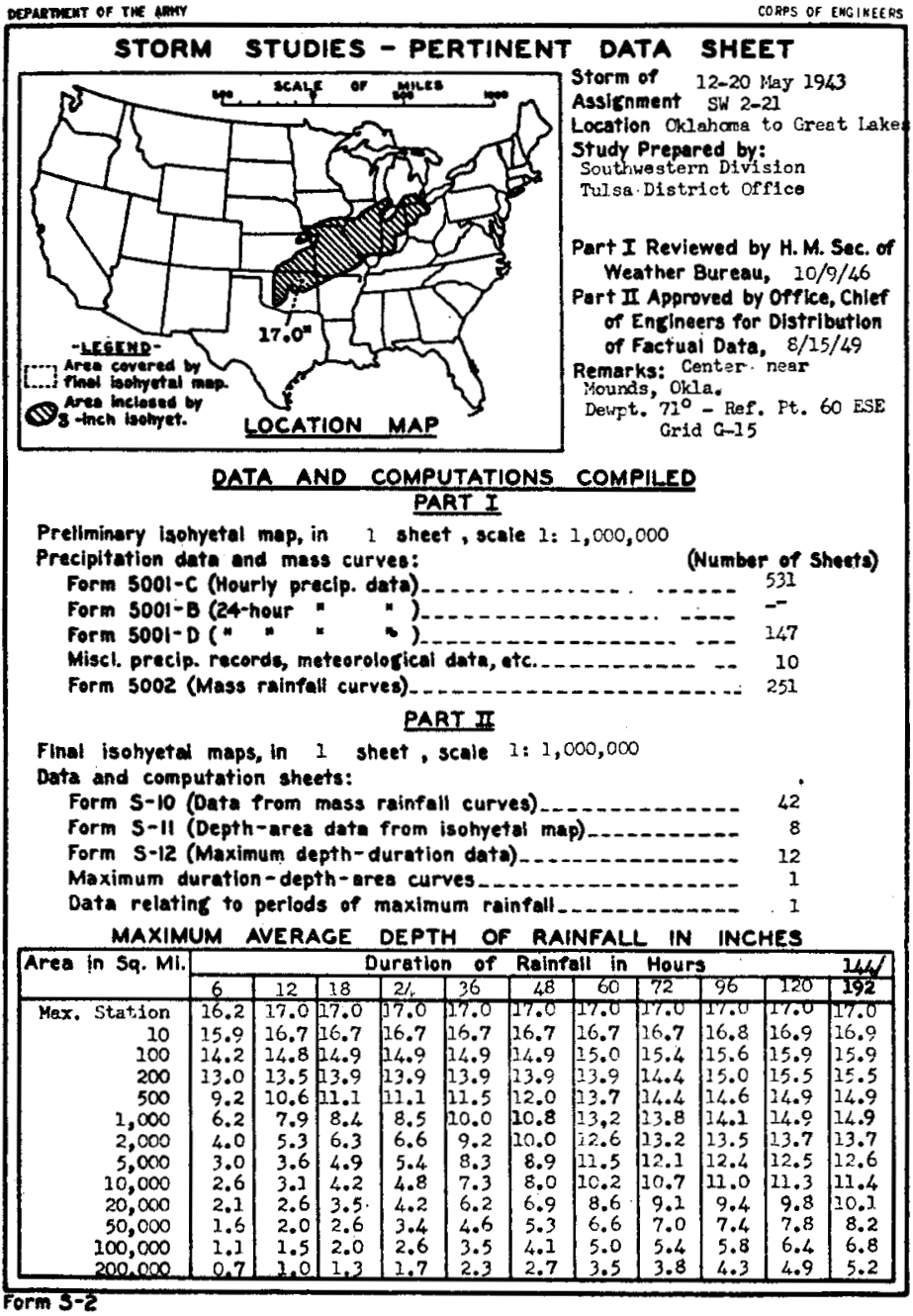

Figure 1.-Example of data sheet for Corps of Engineers storm studies.

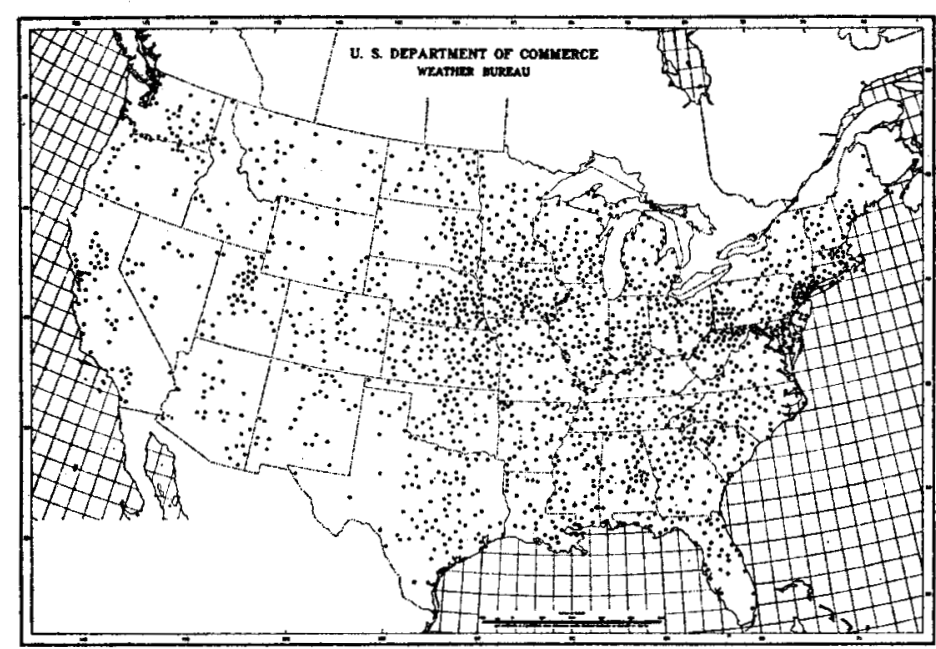

Figure 2.-Stations with 30-year precipitation records, 1906-1935 used in preparing weekly precipitation averages and 4-week charts of average daily precipitation intensity.

\section{SEASONAL VARIATION OF INTENSE PRECIPITATION AS PERCENTAGE OF MAXIMUM}

For each climatological division east of the Rockies all weekly averages greater than one inch were plotted at the appropriate week on a seasonal graph. It was felt that the sparsity of data, irregularities in size and shape of areas, and topographic influences precluded generalized studies of this sort for the western States. Figure 4 shows such a plot for western Tennessee, one of the 94 divisions studied. (The circled values are associated with storms already studied in the Corps of Engineers storm study program. Charts of this sort serve as good indicators of storms worthy of further study in the program.) On each such chart were drawn three curves; the highest curve representing an envelopment of observed weekly average rainfalls over the particular division, and the lowest representing the smoothed weekly averages obtained for the 30-year period. It will be noted that the smoothed weekly means indicate peaks of rainfall on the 13th and 14 th weeks and again on the $52 \mathrm{~d}$ week, whereas the enveloped values indicate a single peak on the $3 d$ week. It is apparent from the plotted values that the double peak on the smoothed average curve results from a greater frequency of 2 - and 3 -inch amounts during that time of year-a significant fact in connection with water supply problems. However, from the viewpoint of spillway, flood reservoir, or levee design, the variations of the extreme or near extreme values are of primary interest.

Figure 5 shows the weekly precipitation over eastern Texas for the period 1906-1935, and again the highest curve represents envelopment of all observed values and the lowest curve represents the smoothed weekly means. The latter curve indicates two peak periods of rainfallthe 17 th and the 49 th and 50th weeks, again resulting from a predominance of weeks having 2- and 3-inch amounts of precipitation. In sharp contrast, the enveloping curve shows a marked peak at the $33 \mathrm{~d}$ week with indications of secondary peaks on the 13 th and 49 th weeks. The peak on the enveloping curve is a result of weak tropical storms moving inland over the Texas areainfrequent for a particular area but not uncommon for the region adjacent to or just inland from the Gulf of Mexico. Such chance occurrences over a particular division tend to create an unstable curve of enveloped observed values which is highly dependent upon the combination of length of record and chance occurrences. From an engineering design viewpoint it is desirable to have a more stable curve upon which to base design estimates.

The middle curves in figures 4 and 5 , labeled 99 percent, represent a seasonal distribution of intense rainstorms of unusual but not rare occurrence. Considerable judgment has gone into the drawing of these curves. Certain general rules can be enumerated as follows:

1. The data should serve as basic guides. 


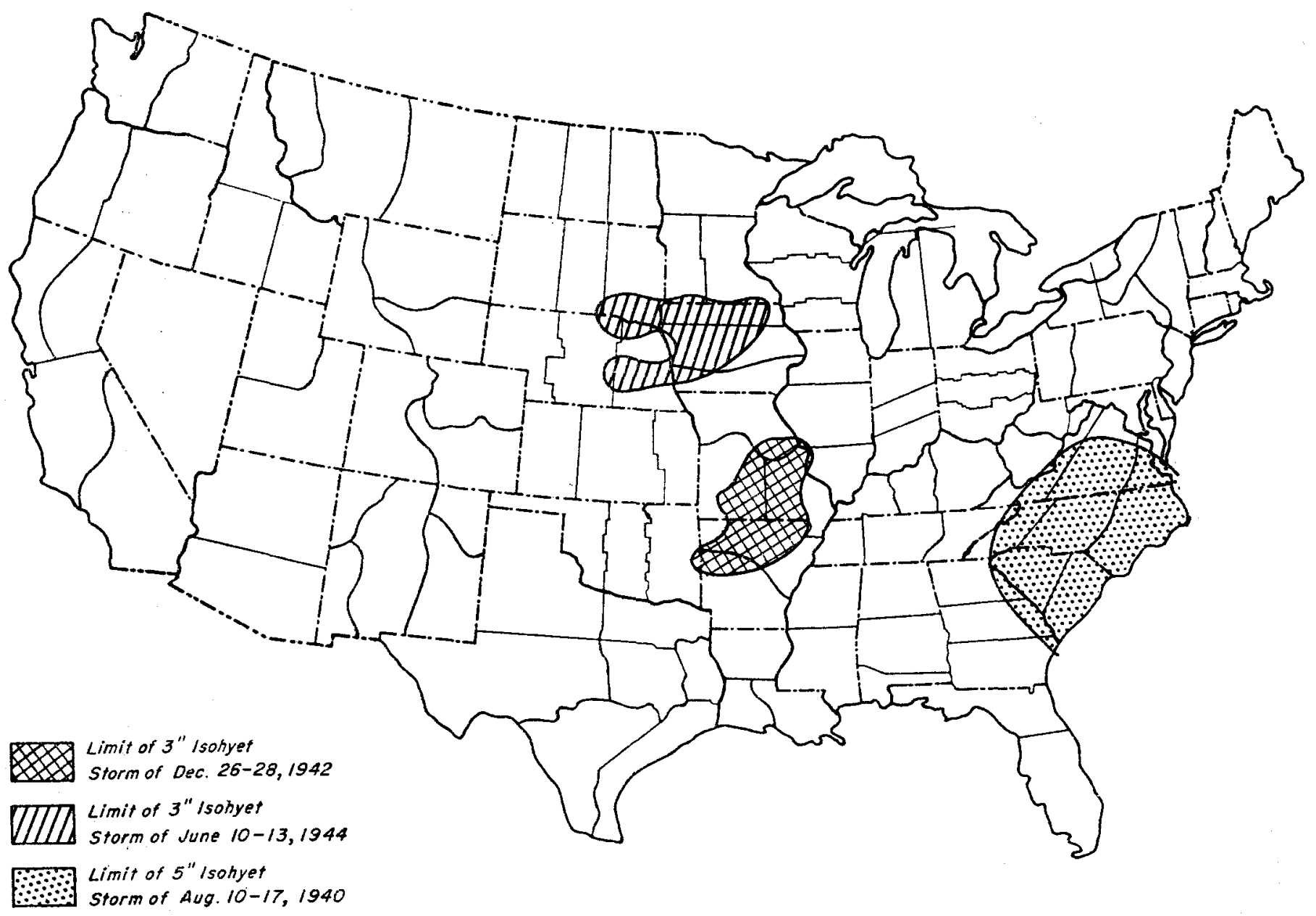

Figure 3.-Base map shows climatological divisions of the United States. Hatched areas show limits of heavy rain in three selected storm situations.

2. The curves should be fairly smooth, exhibiting no sharp discontinuities from one week to the next. The intent of this rule is not to deny the existence of singularities, but rather, to recognize the extreme difficulty in the proof of such singularities - a good number of which appeared to be indicated over the span of 30 years.

3 . The number of points undercut on each seasonal graph should be approximately 15,16 or 17 (approximately 1 percent of the total, 1,560 weeks). Some latitude had to be allowed in order to permit smoothing of curves to avoid sharp irregularities.

4. The points undercut should be fairly evenly distributed throughout the year.

5. The amount of undercutting of a particular point should be dependent upon the number of other high intensity values for that season and especially upon the clustering of points on or just below the tentative curve.

6. The curve for a particular division should be consistent with the curves of adjacent divisions with due consideration for topographic variation, geographic location with respect to moisture source, and variation in area of the climatological divisions.

The "99 percent curves" represent a first approximation to the seasonal variation of intense weekly precipitation over particular large areas. It is believed that a reasonable representation has been achieved in spite of the considerable degree of subjectivity required for the final lines. Furthermore, it is believed that, given the same basic data, another analyst following the general rules prescribed would obtain approximately the same curve. As an additional check upon the shape of the 99-percent curve, an additional curve was drawn undercutting approximately 78 points throughout the year $(95$ percent) whenever doubts arose concerning the shape of the 99-percent curve.

The size, shape, and orientation of storm isohyetal patterns as related to the topographic, geographic, and areal characteristics of the divisions play an important 


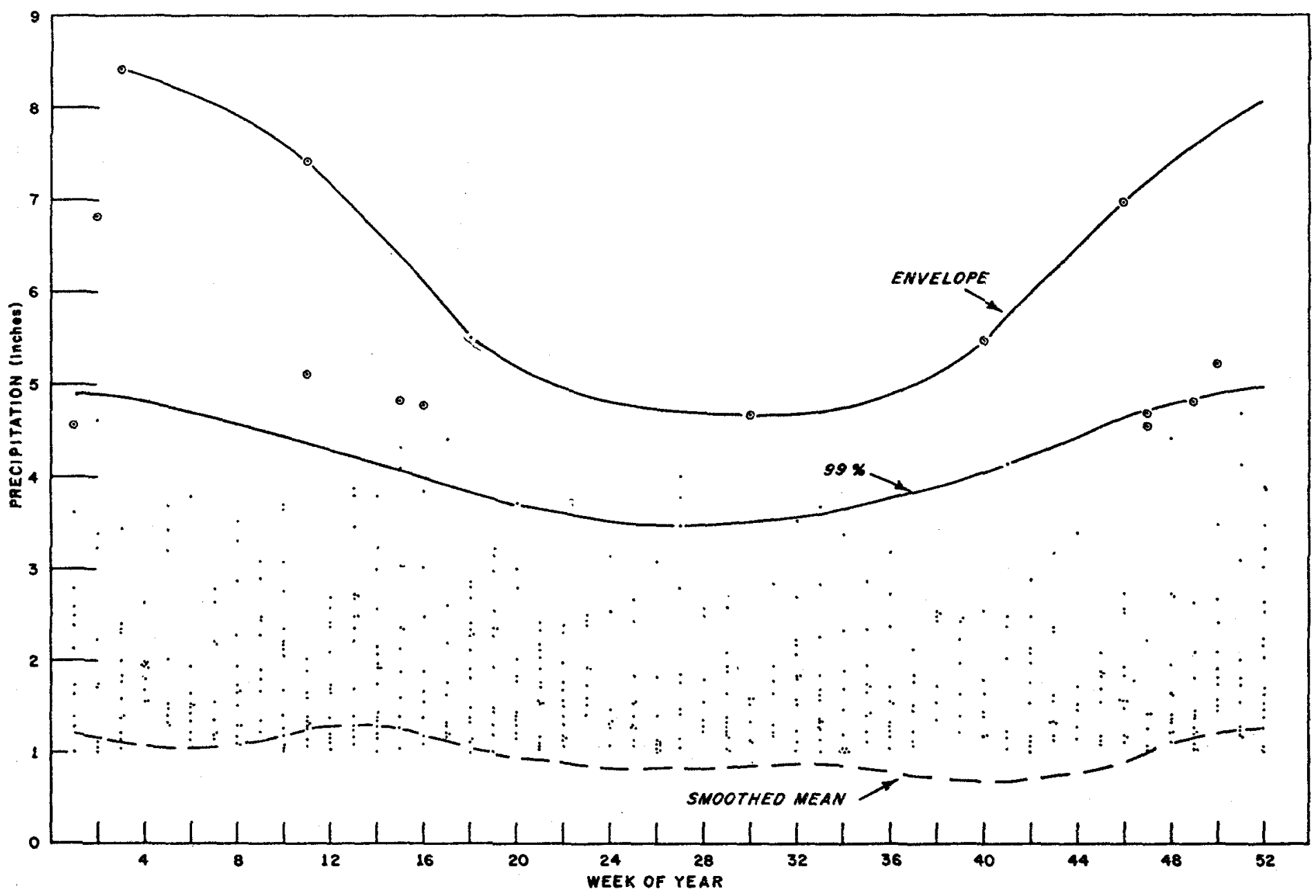

Figune 4.-Western Tennessee weekly precipitation greater than 1 inch, 1906-35. Circled dots are weekly totals greater than 4.5 inches, studied by Corps of Engineers.

role in the evaluation of seasonal variation. From figure 3 , it is seen that a particular storm may be a good or poor match for selected areas of study such as States, climatological divisions, counties, or other arbitrarily bounded regions. Actually, the only completely adequate way of handling such a problem is to examine different orientations, shapes, and sizes separately as is done in the Corps of Engineers Storm Study Program. For hydrologic studies individual river basins are examined in detail as the problem arises. Because of the deptharea relationships, comparison of average amounts of precipitation in inches loses much of its meaning whether on a State, division, or county basis.

Therefore, a set of charts (dashed lines in figures 6-31) is presented as a generalized portrayal of seasonal variation of precipitation over large areas. These charts are the result of an additional step in smoothing which partly compensates for the differences in shape, size, and orientation. For each division, at bi-weekly intervals the ratio of the value of the 99 percent curve to the maximum value of the 99 percent curve of that division was computed. These values were plotted and smoothed percentage lines drawn. Considerable judgment was again applied in drawing these lines since the areal irregularities became more noticeable. Again certain general rules were adopted as follows:

1. In non-orographic areas smoothness of pattern was considered desirable. For example, a percentage value of 80 surrounded by 90 's was considered a result of shape irregularity and was enveloped. The net effect of this procedure was to modify the basic 99 percent curve for the particular division by increasing its value at that particular time of year.

2. Major orographic features (Appalachians and slopes of Rockies) were allowed to play dominant roles and became boundaries of rather sharp discontinuities. Minor meteorological controls (Ozarks and Great Lakes) were given less consideration. 


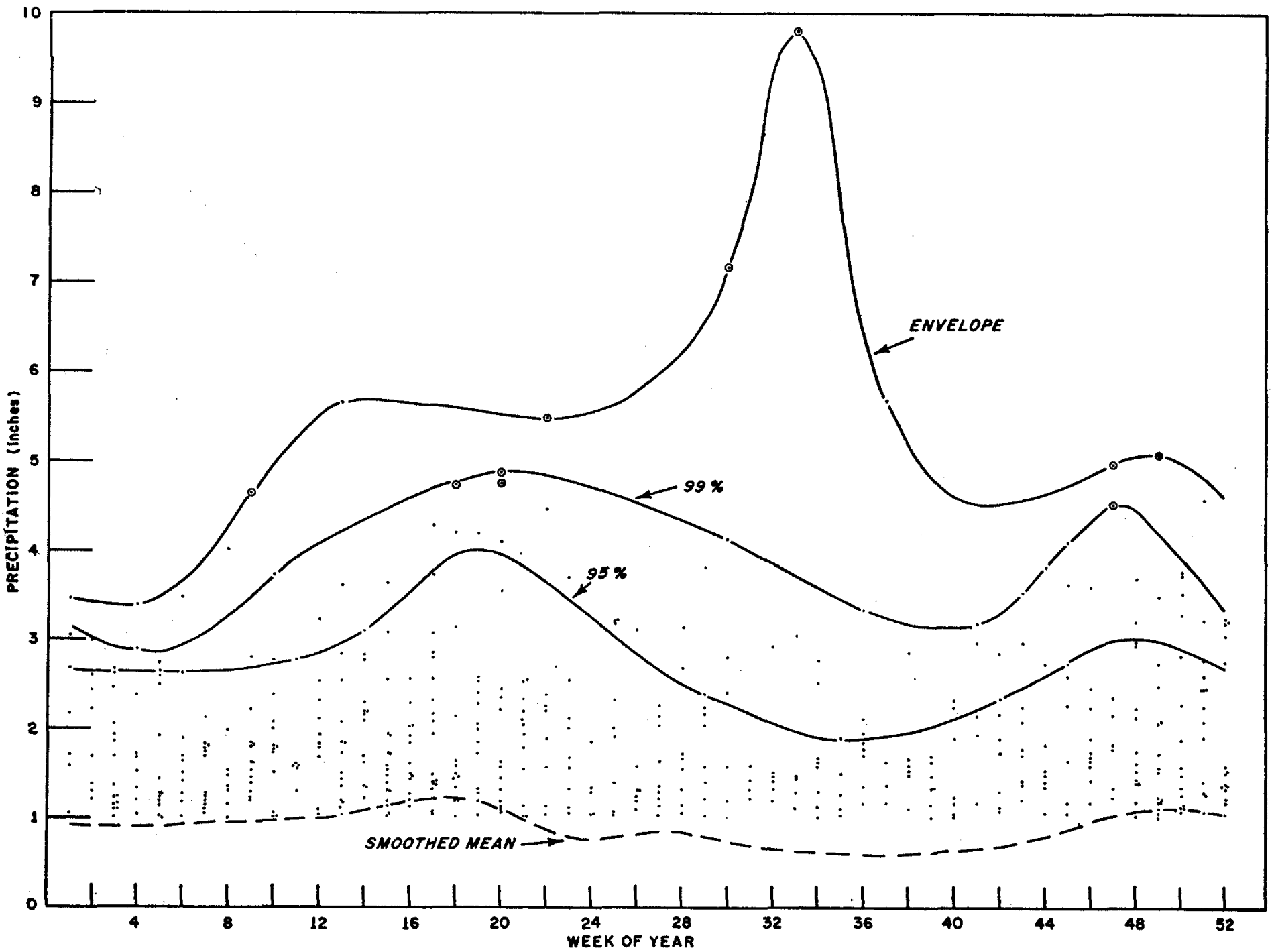

Fraure 5.-Eastern Texas weekly precipitation greater than 1 inch, 1906-35. Circled dots are weekly totals greater than 4.5 inches, studied by Corps of Engineers.

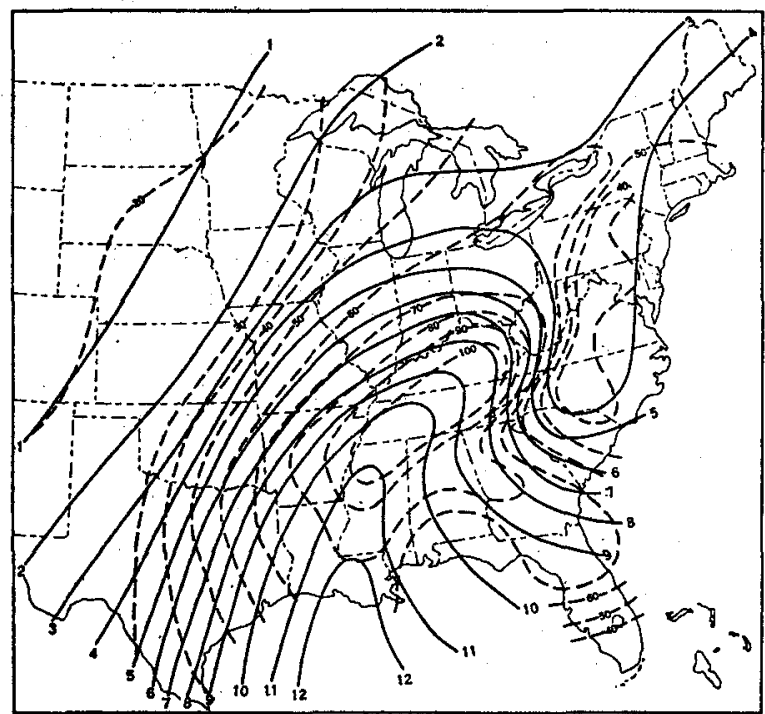

Figure 6.-Percent of maximum value of seasonal variation of precipitation over large areas (dashed lines) and index of intense precipitation in inches (solid lines) for the week January 8-14.

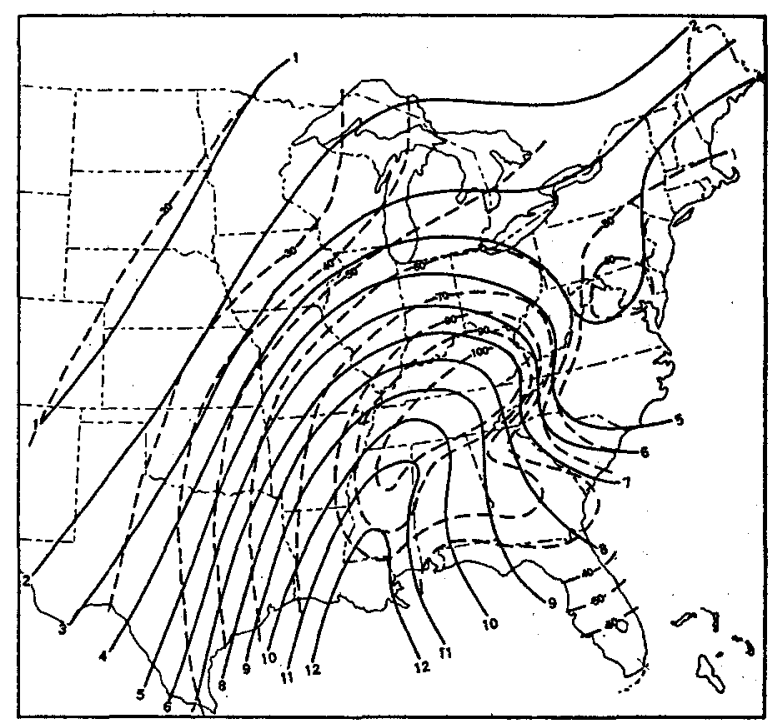

FiguRe 7.-Week of January 22-28. 


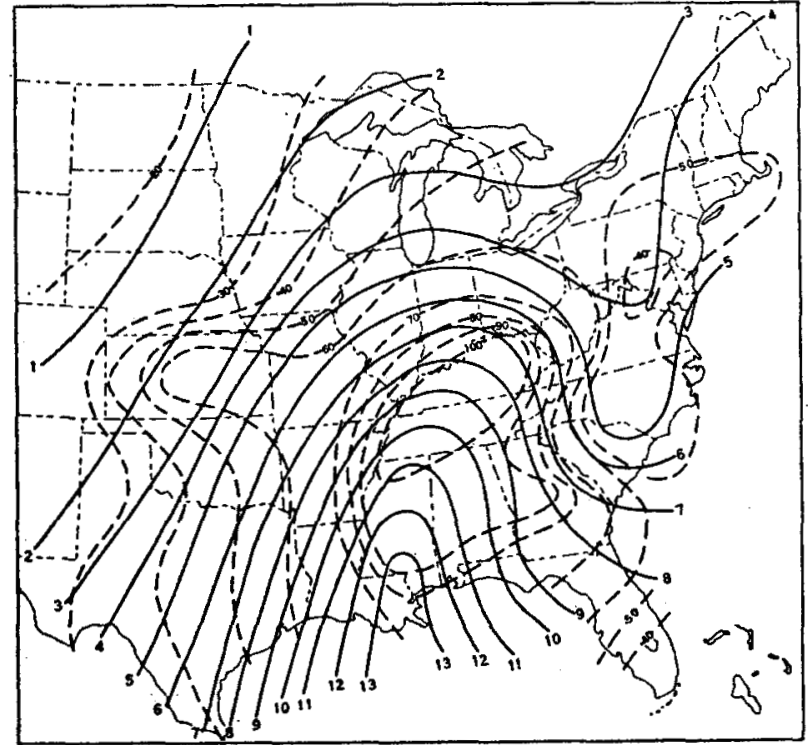

Figure 8.-Week of February 5-11.

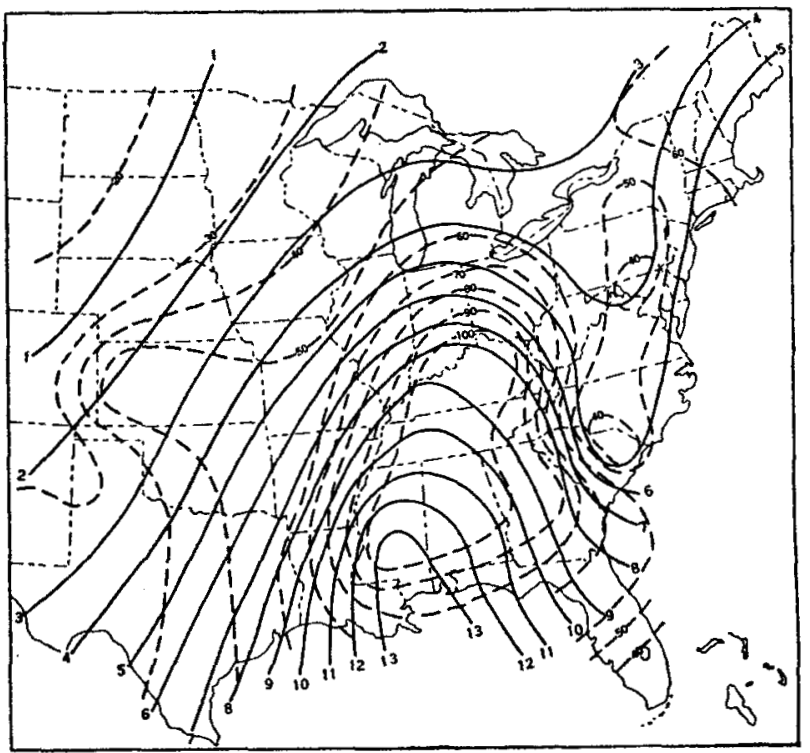

Figore 9.-Week of February 19-25.

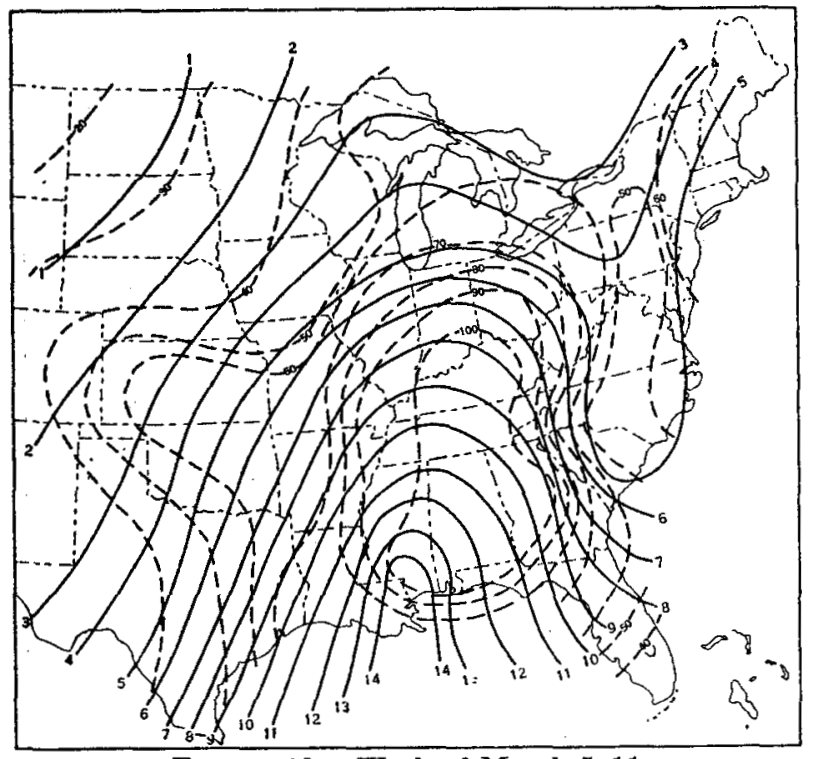

Figurs 10.-Week of March 5-11.

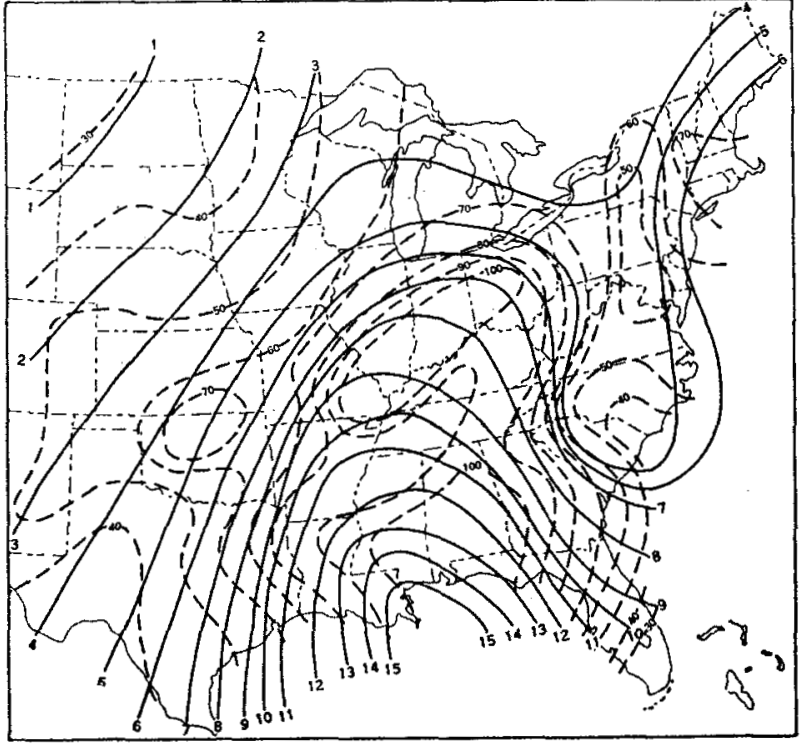

Fraure 11.-Week of March 19-25.

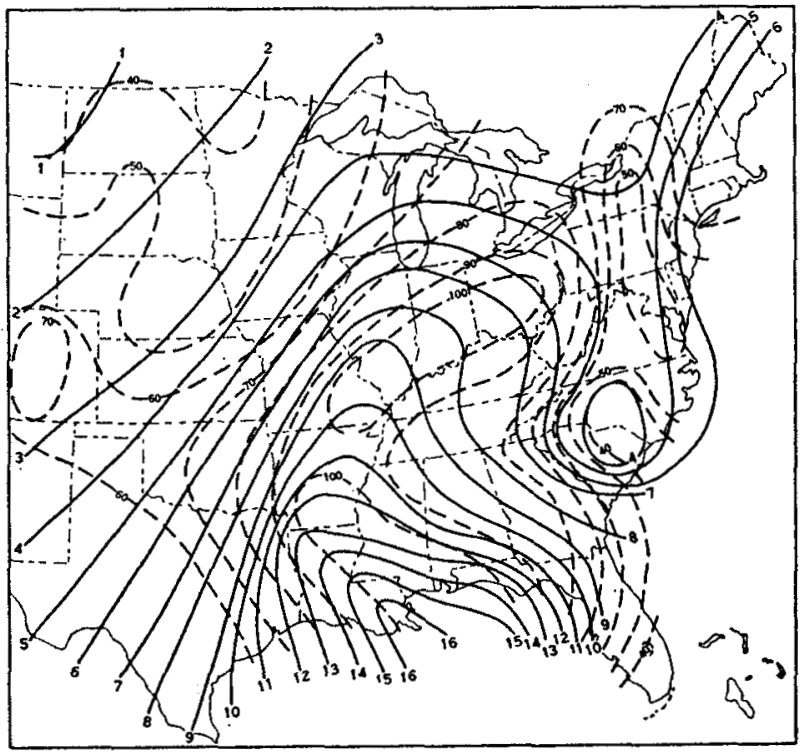

FIgURE 12.-Week of April 2-8.

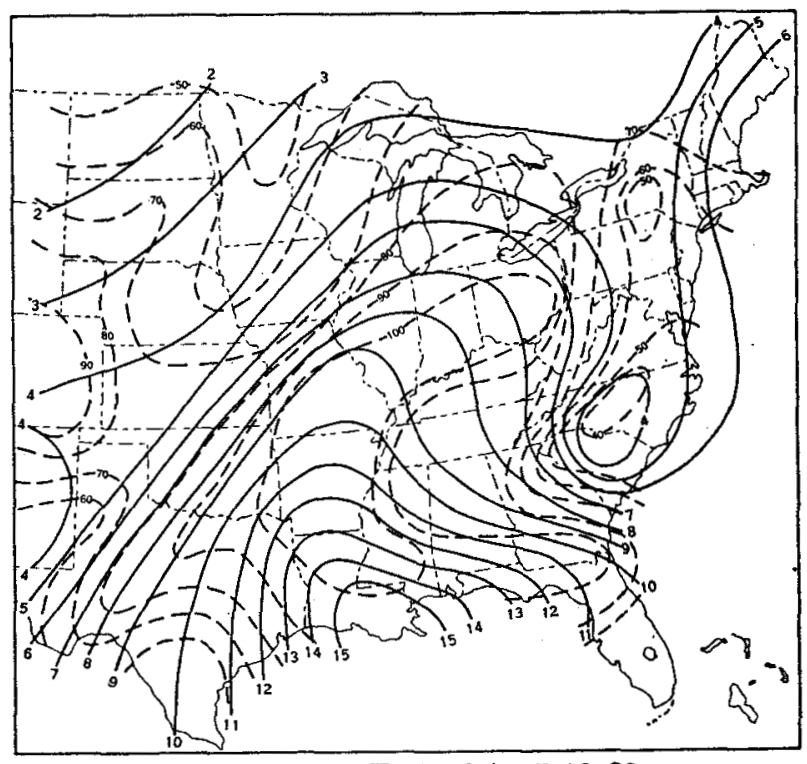

Figure 13.-Week of April 16-23. 


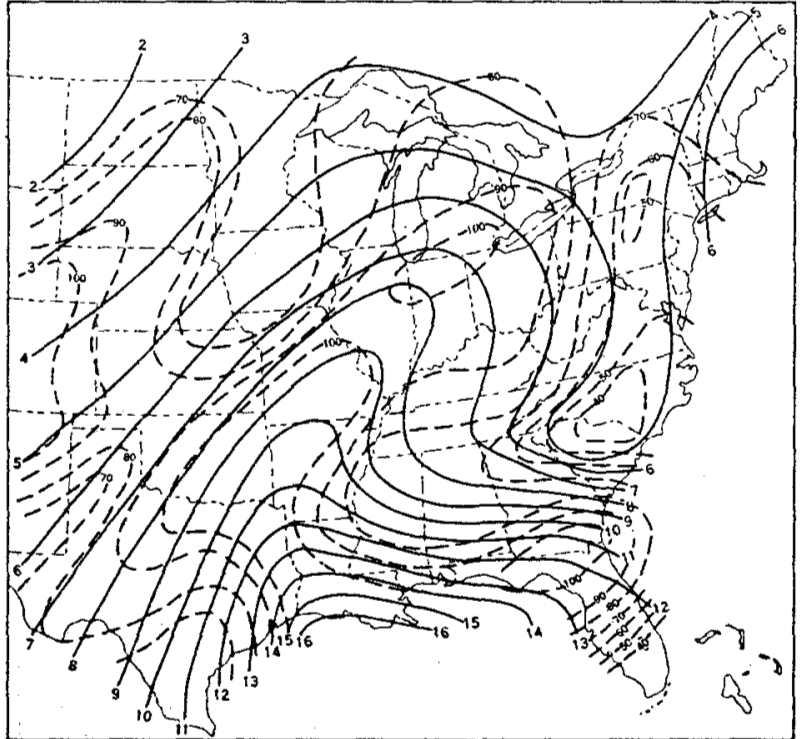

Figure 14,-Week of April 30-May 6.

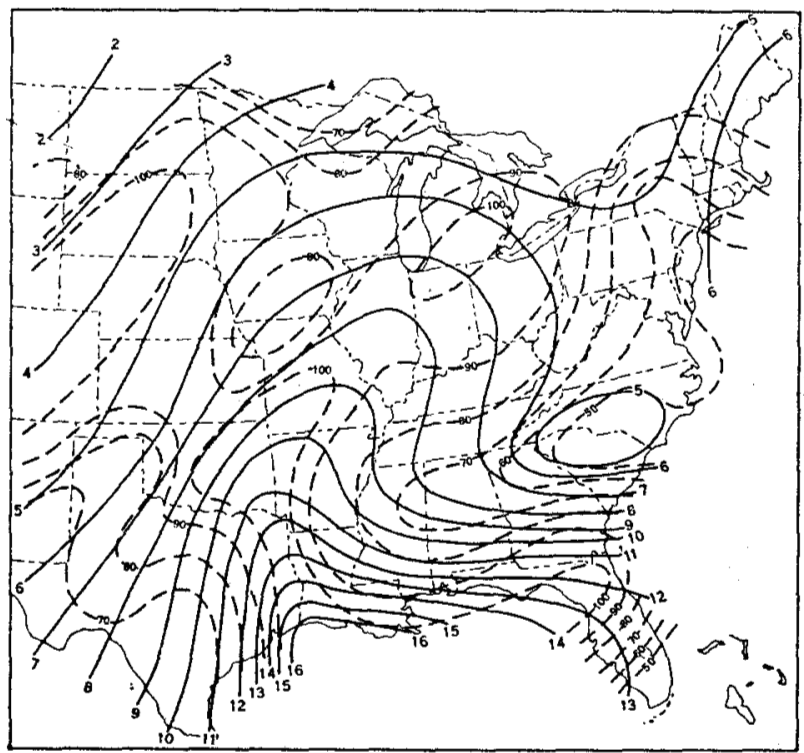

Figure 15.-Week of May 14-20.

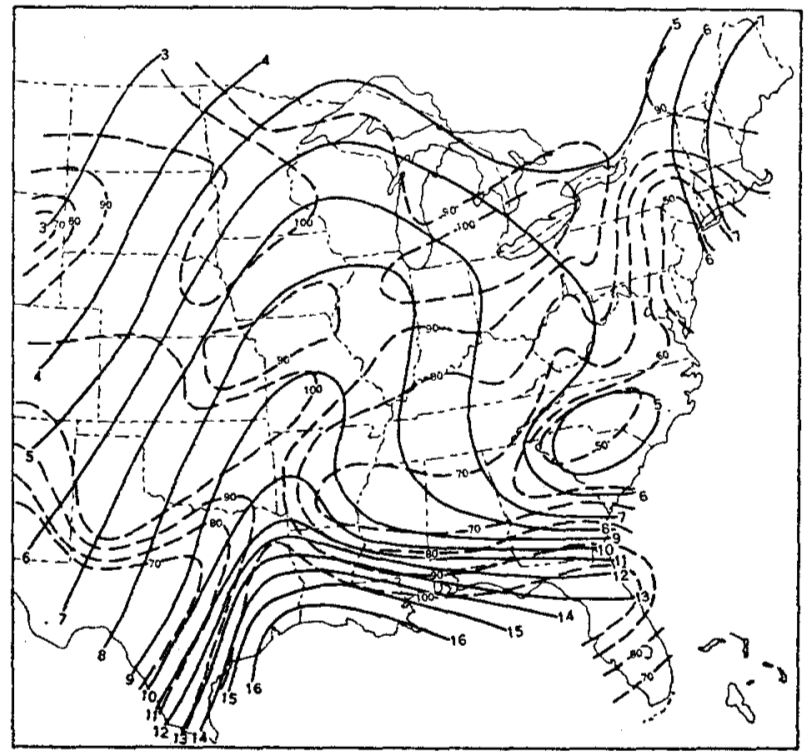

Figure 16.-Week of May 28-June 3.

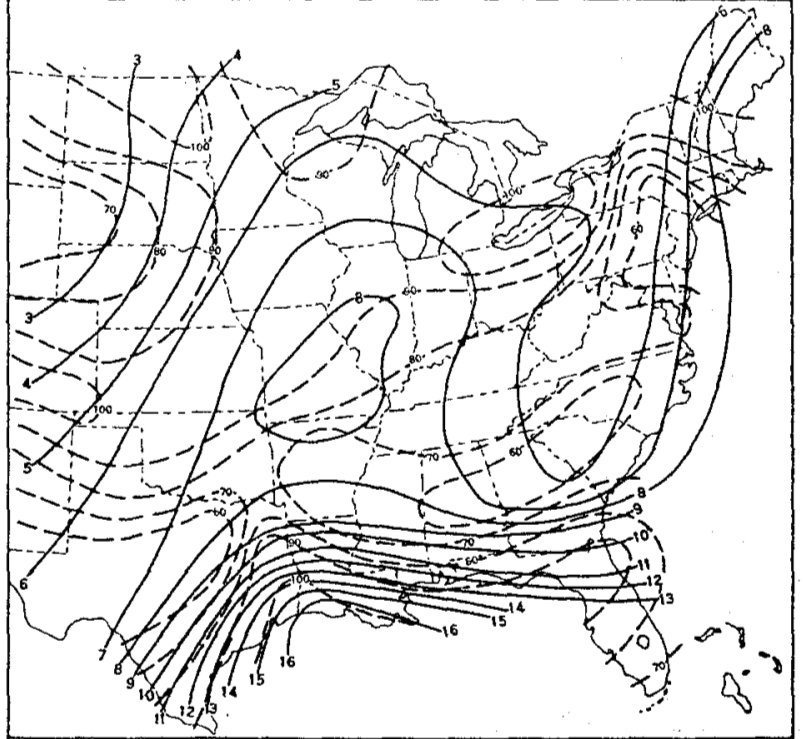

Figure 17.-Week of June 11-17.

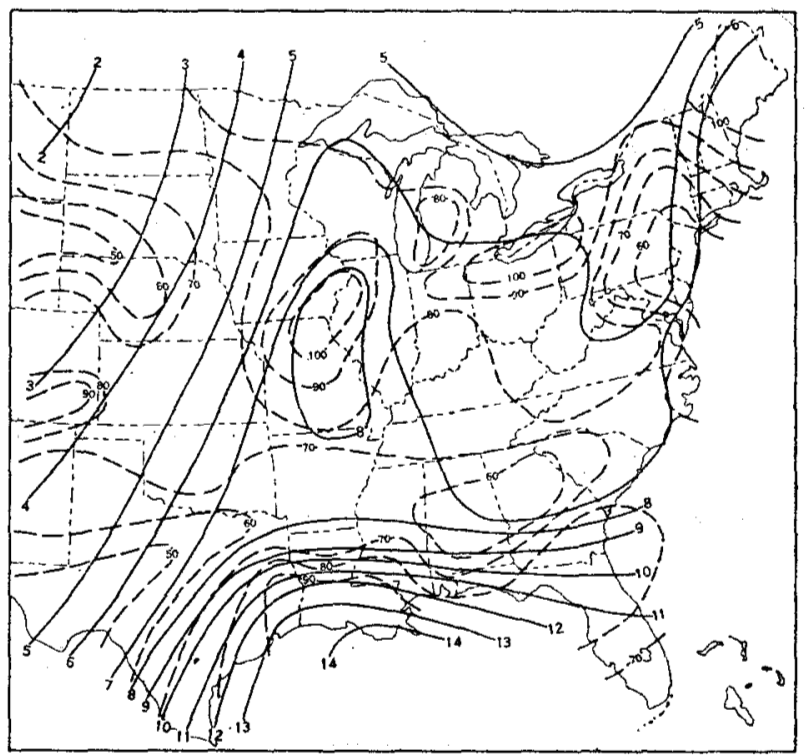

FiguRe 18.-Week of June 25-July 1.

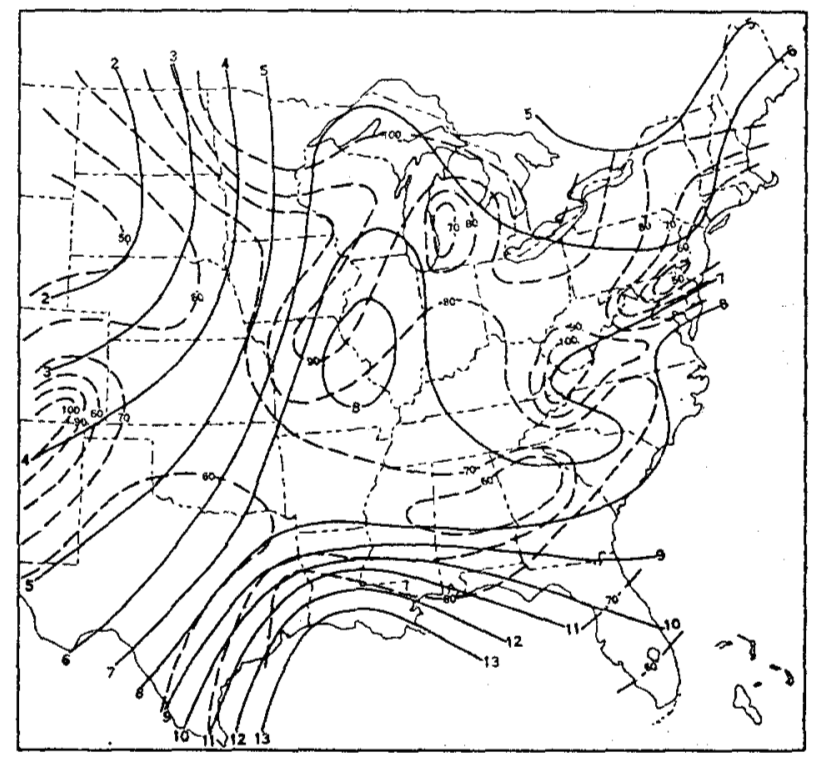

Fraune 19.-Week of July 9-15. 


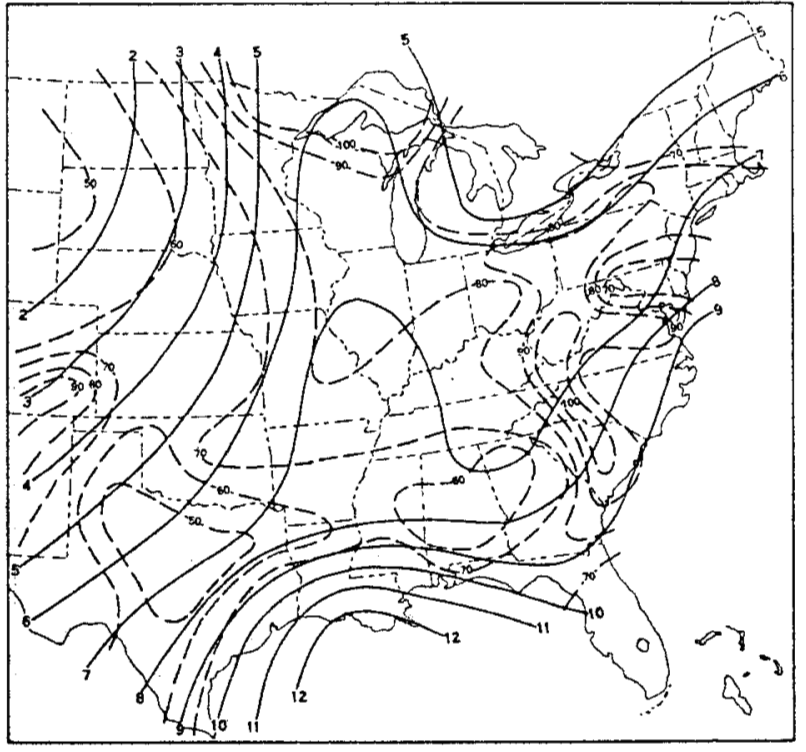

Frgure 20.-Week of July 23-29.

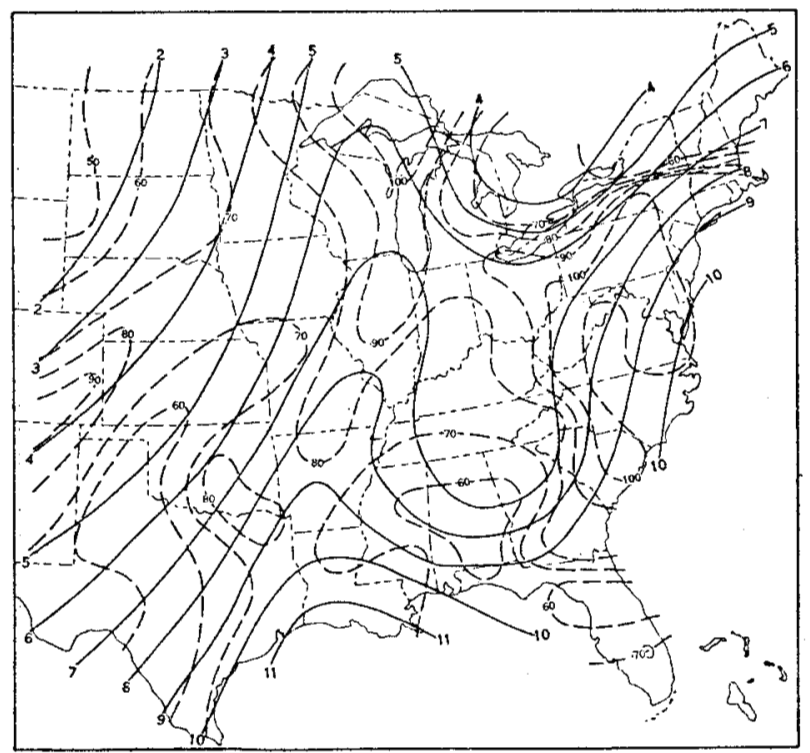

Figure 21.-Week of August 6-12.

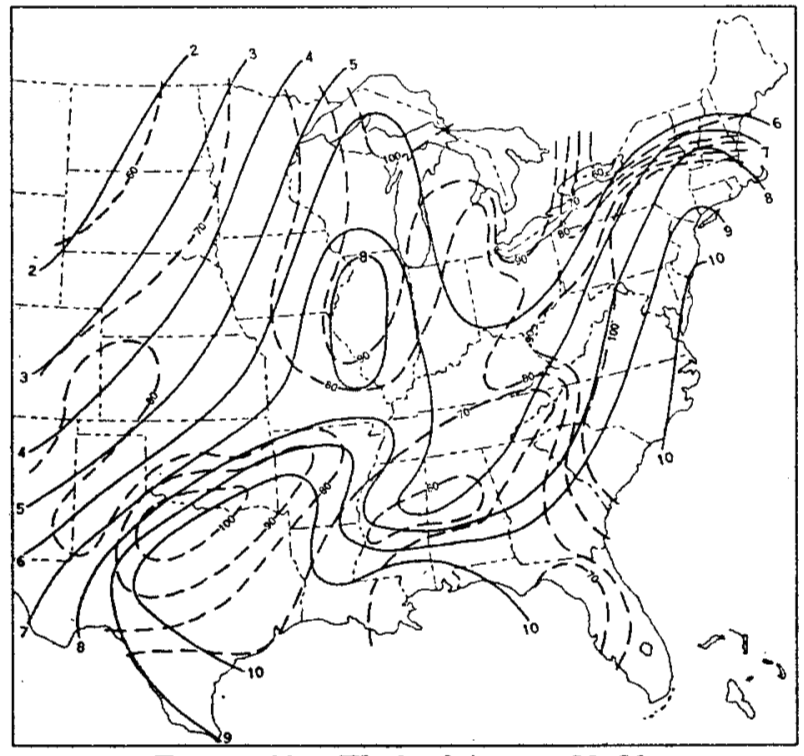

Figure 22.-Week of August 20-26.

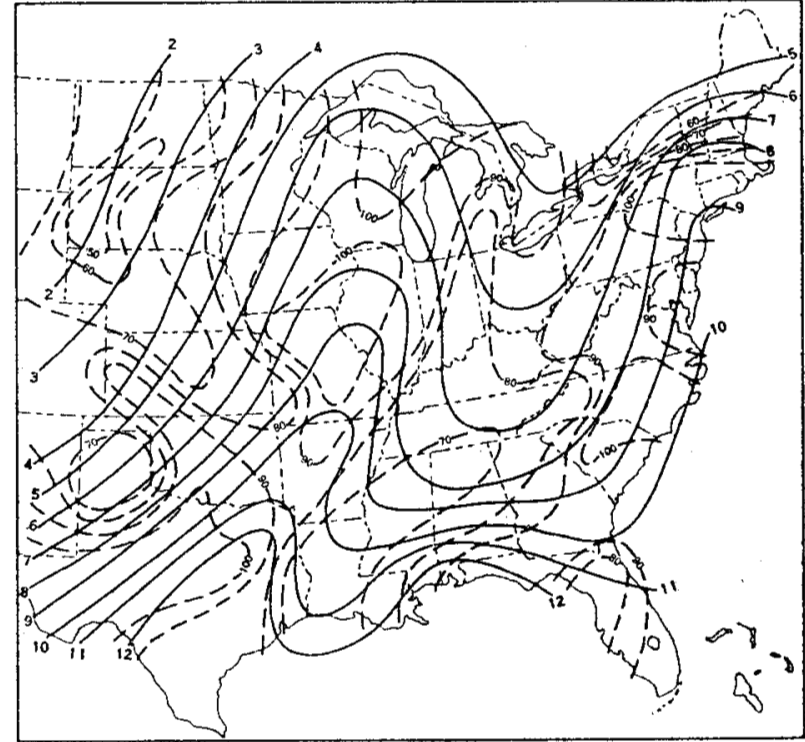

Figure 23.-Week of September 3-7.

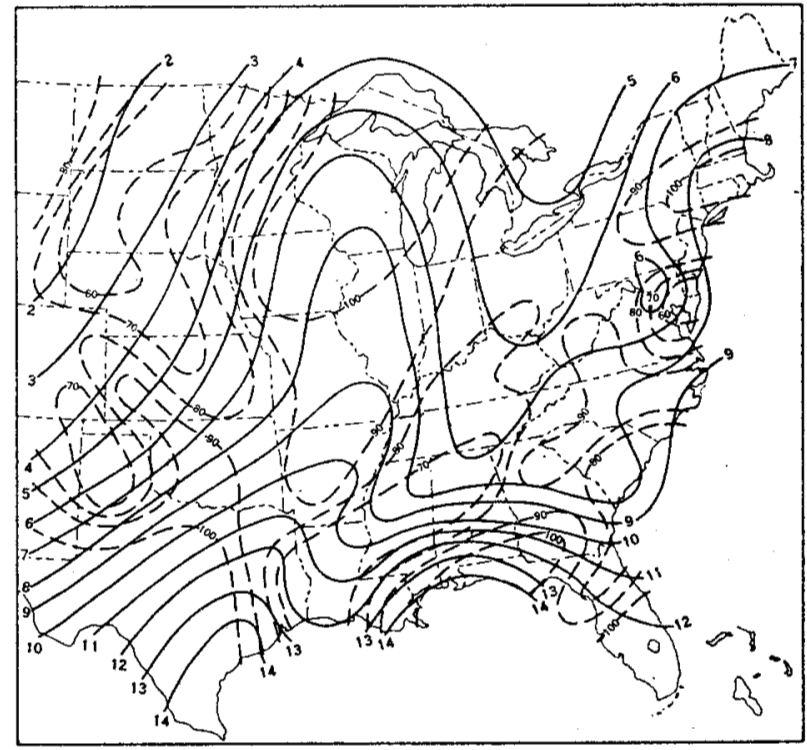

Figure 24.-Week of September 17-23.

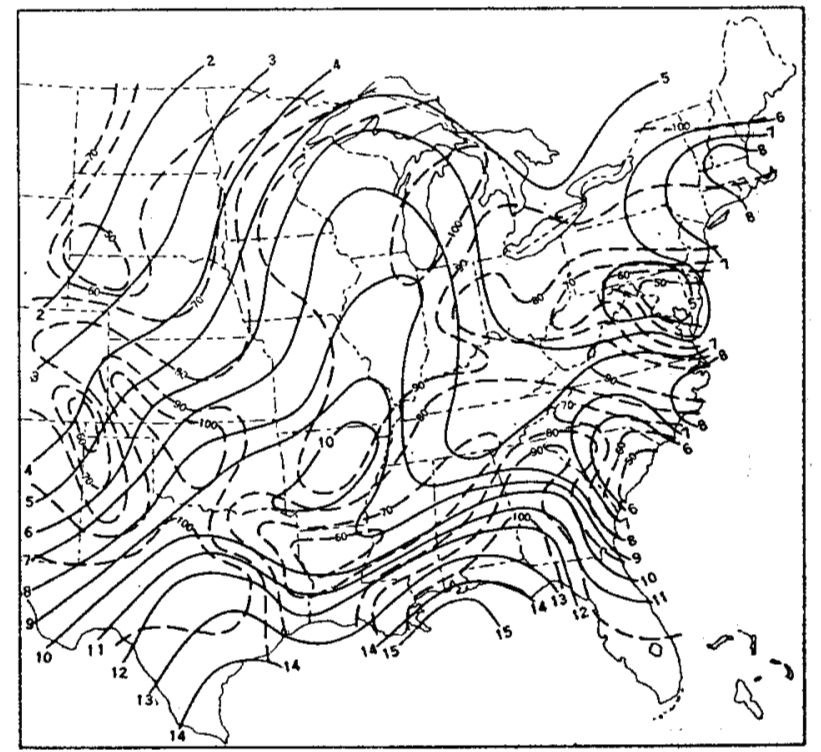

Fiaure 25.-Week of October 1-7. 


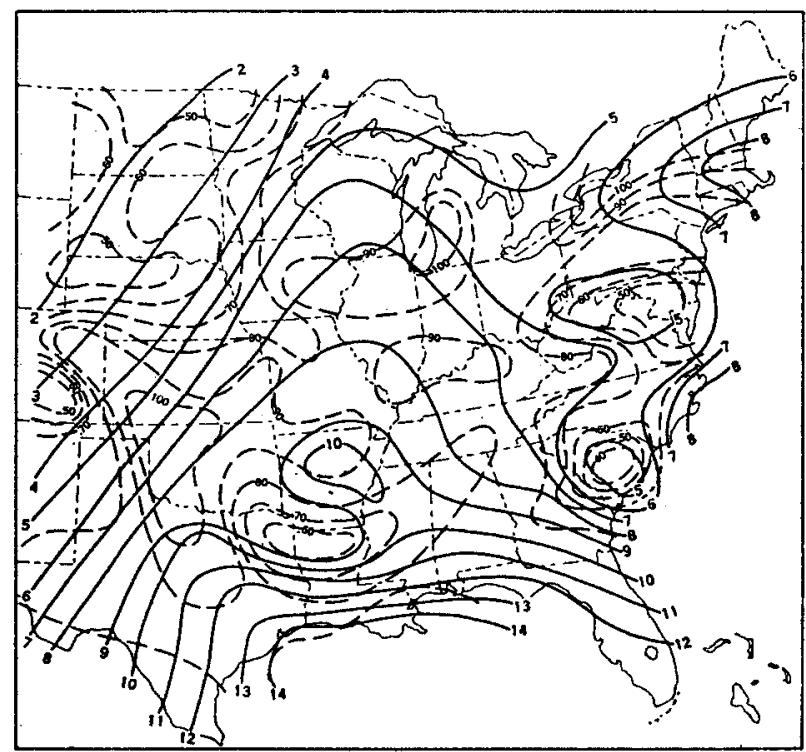

Frgure 26.-Week of October 15-21.

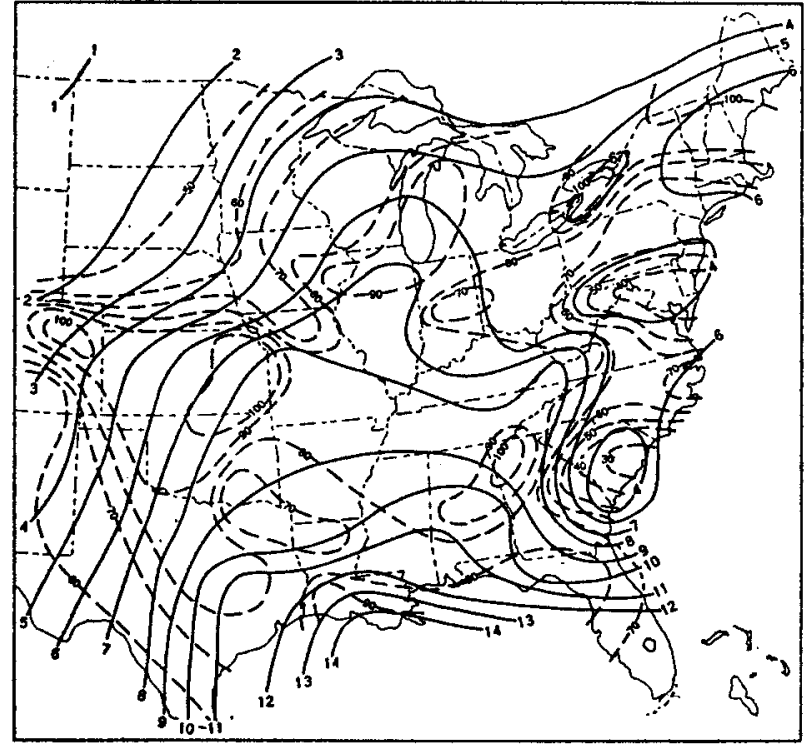

Figure 27.-Week of October 29-November 4.

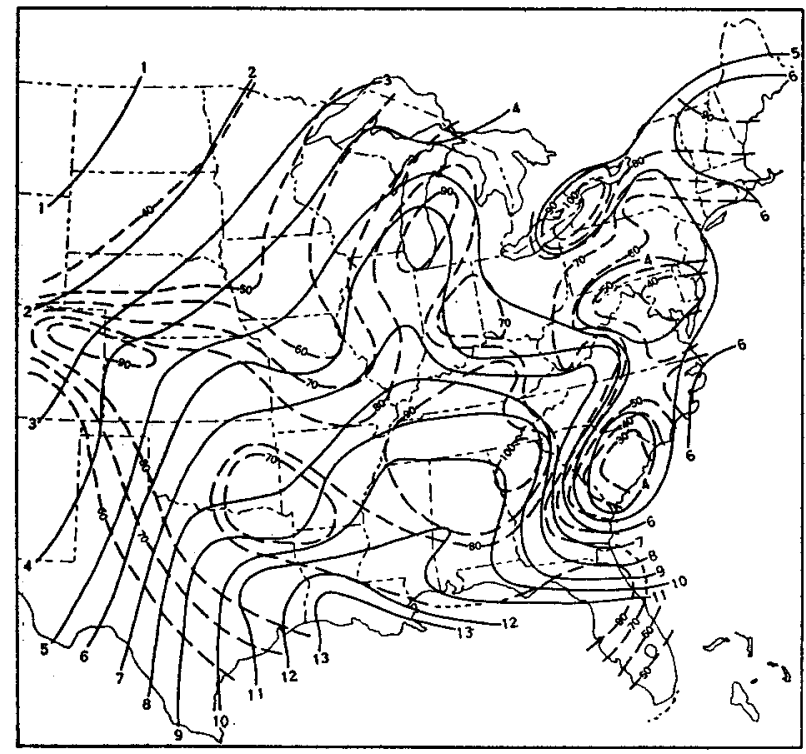

Frgure 28.-Week of November 12-18.

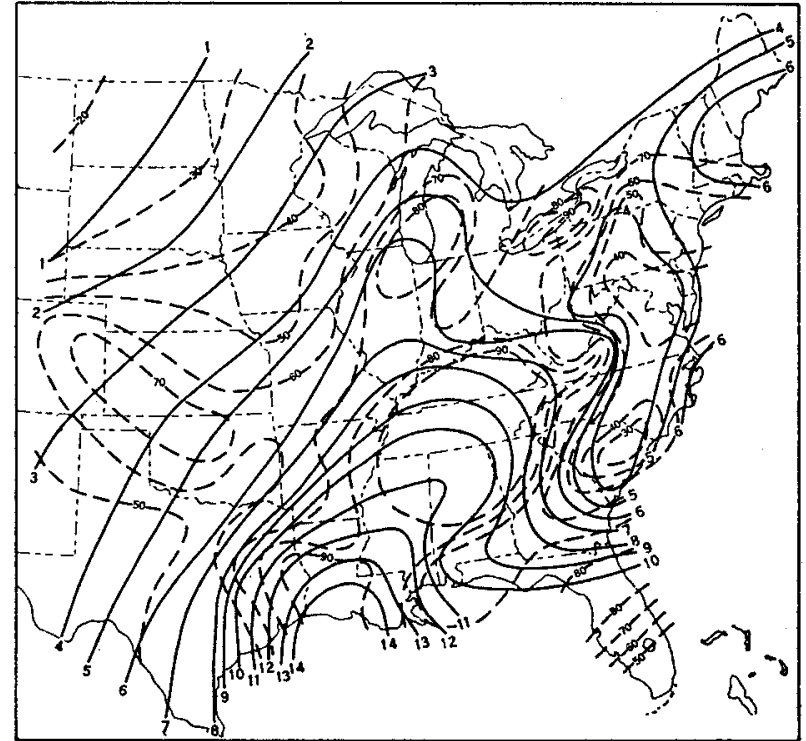

FigURE 29.-Week of November 26-December 2.

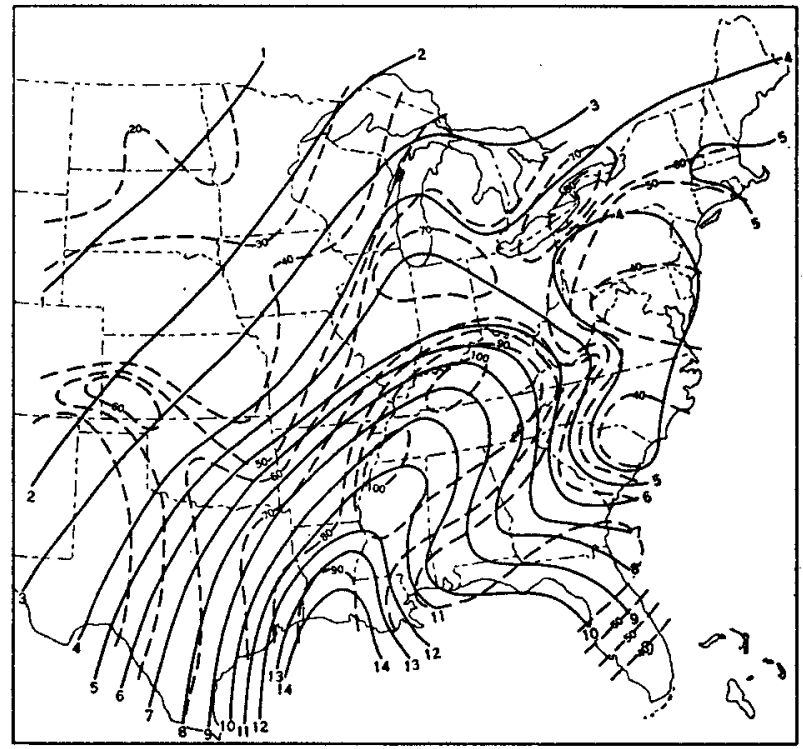

Figure 30.-Week of December 10-16.

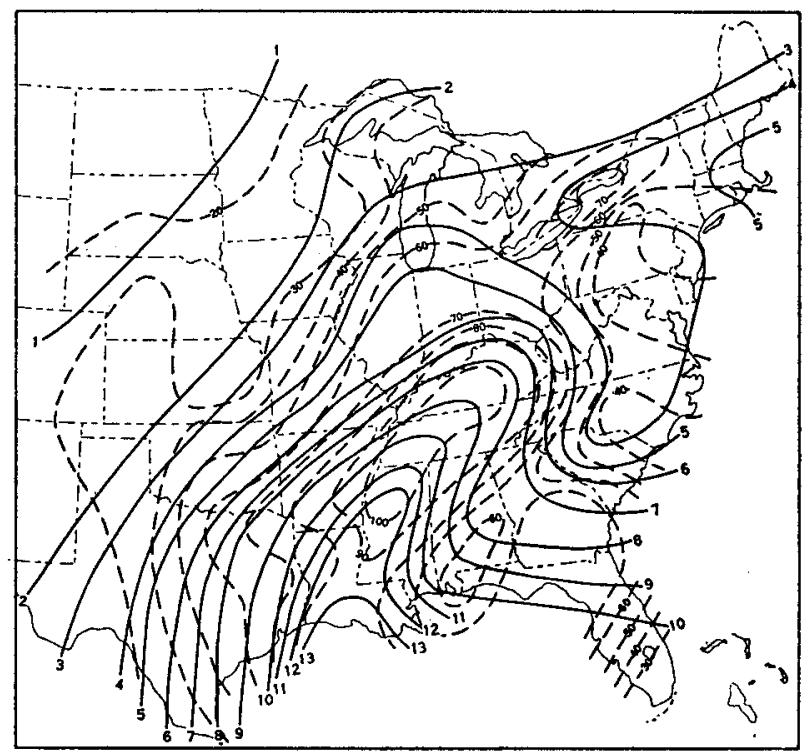

Fraune 31.-Week of December 24-31. 


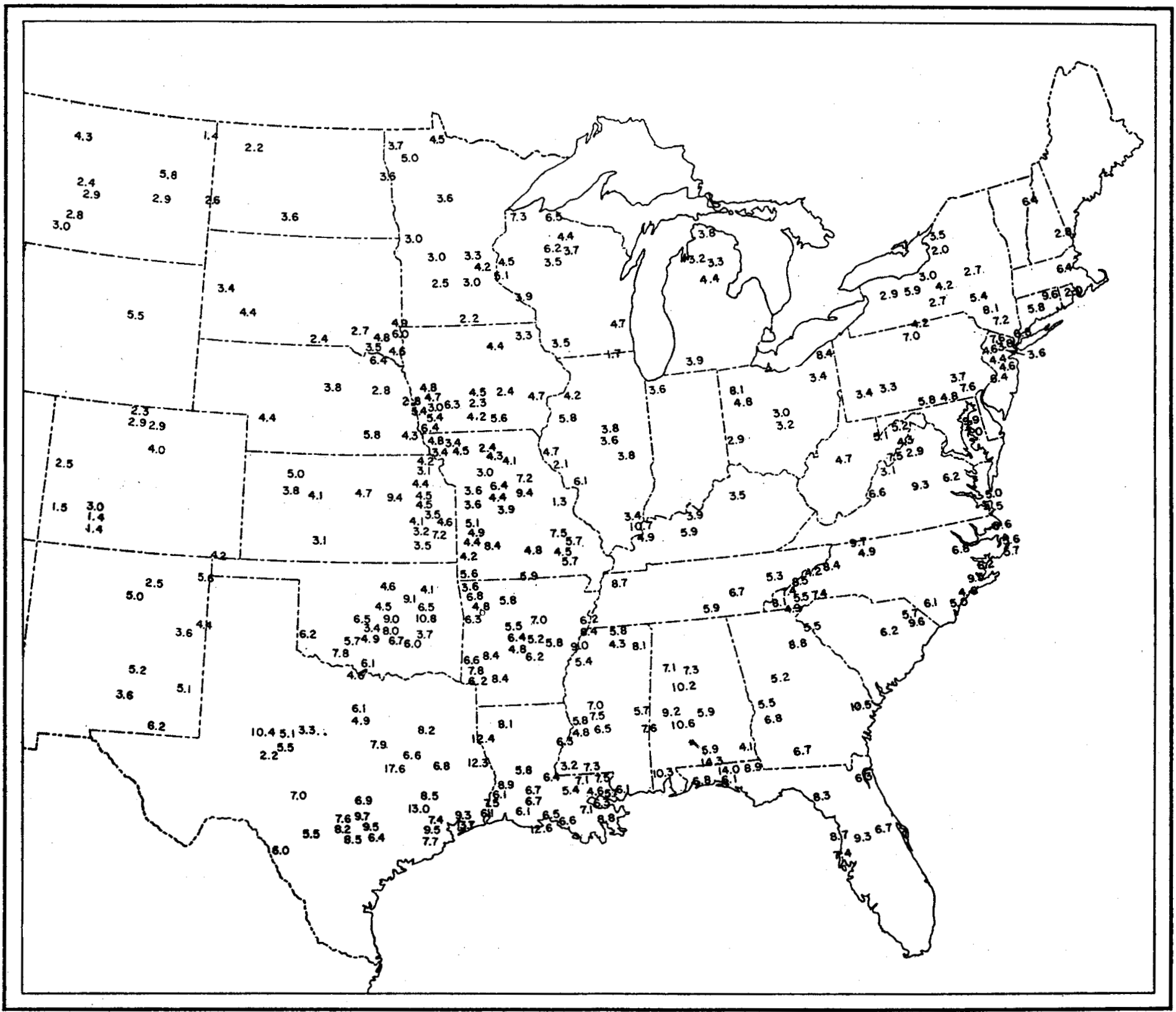

Figure 32.-Storm Rainfall. Average depth of precipitation over 20,000 sq. mi. in 72 hours. (From Corps of Engineers Storm Studies.)

3. Experience with major storm studies of the Corps of Engineers Storm Study Program with regard to season and place of occurrence of major storms influenced the final drawing of isolines when doubt existed.

4. From a practical and safety viewpoint there was a tendency to overdraw rather than underdraw percentages. For example, values of 95-100 percent may have been encircled by the 100 percent line in order to catch peaks which might fall to either side of the bi-weekly chart dates.

\section{EMPIRICAL INDEX OF SEASONAL VARIATION OF PRECIPITATION}

So far, a portayal of the seasonal variation of weekly precipitation over moderately large areas in terms of percentage of a maximum value has been established. The next step was to evaluate a base for maximum values at particular locations. Figure 32 is a plot of all observed 20,000-square-mile, 72-hour storm values from the Corps of Engineers storm studies regardless of season of occurrence. These values can serve as a base for maximum values provided a suitable portayal of areal variation can be obtained. The monumental proportions of a storm study program with the intent of obtaining a complete array of storm values for all areas of the country and all seasons of the year has precluded this method of approach. It should be noted that the selection of storms studied in the program is based upon intensities, total volume of rainfall, associated floods, availability of suit- 


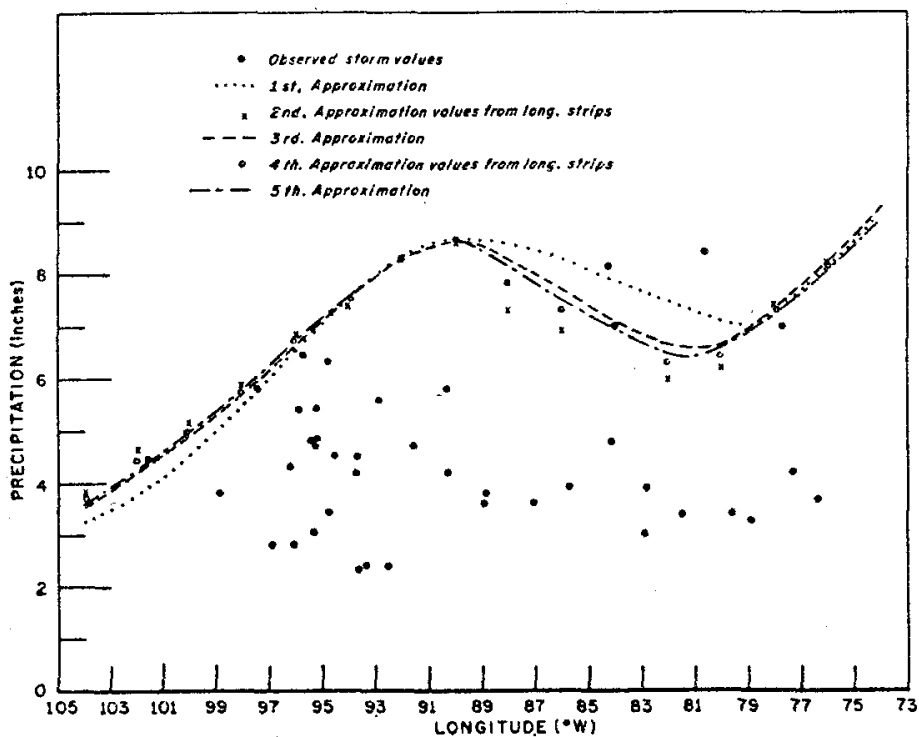

Frgure 33.-Average depth of storm rainfall over 20,000 sq. mi. in 72 hours according to longitude for the latitudinal strip $40^{\circ}-42^{\circ} \mathrm{N}$.

able rainfall measurements, and work load of the Engineers field offices. It can readily be seen that no frequency or expected-return period could be assigned to a particular storm. As objective a method as possible was desired to reduce, if possib]e, the observed storm values to base values representing approximately equal likelihood of occurrence.

The eastern part of the United States was divided into $2^{\circ}$ strips of latitude and longitude. Storms values from within each $2^{\circ}$ strip of latitude were plotted on a graph with longitude as abscissa and depth of precipitation as ordinate, as shown in figure 33 . All storms within each $2^{\circ}$ longitude strip were plotted with precipitation as abscissa and latitude as ordinate (fig. 34). A first approximation to the distribution of depths was drawn (dotted line) considering values on adjacent strips by means of overlay comparison. On these graphs a number of storm values were undercut since the values were far and away greater than all other values in the neighborbood. One limitation placed upon undercutting was that the storms undercut be fairly evenly distributed over the country. Values read from the visually fitted curves of latitudinal strips were than plotted on the longitudinal strips (X's). Curves of second approximation (dashed lines) were then drawn, roughly splitting the difference between the first approximation and the points obtained from the latitudina] strips. From the dashed lines on the longitudinal strips, then, values were plotted on the latitudinal strips (X's), providing a basis for a third approximation on the latitudinal strips. Additional approximations reduced the remaining differences to the order of several tenths of an inch which was considered a sufficient degree of accuracy.

Values taken from the very last approximation were then plotted on a map and a smooth pattern (fig. 35) was obtained which, it is believed, represents, approximately,

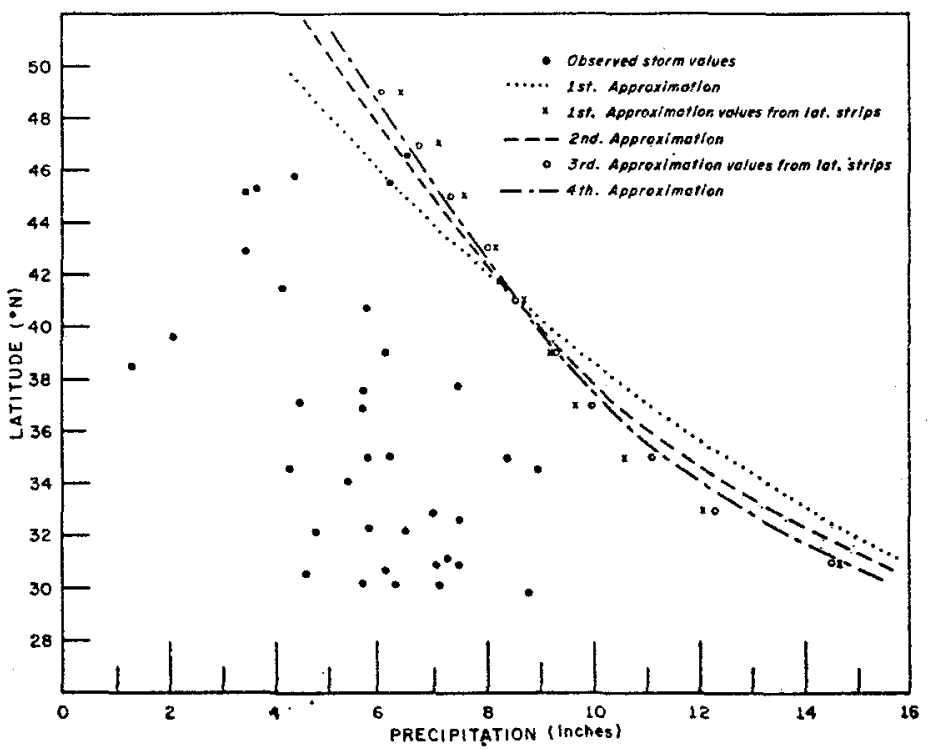

Frgure 34.-Average depth of storm rainfall over 20,000 sq. mi. in 72 hours according to latitude for the longitudinal strip $89^{\circ}-$ $91^{\circ} \mathrm{W}$.

the depths of precipitation having equal likelihood of occurrence over the country for areas of 20,000 square miles and duration of 72 hours. Observed storm precipitation undercut by this pattern is shown in figure 35 . It is believed that (having been derived from observed data) figure 35 represents a picture of precipitation depths resulting from near-maximum combinations of rainfallproducing mechanisms regardless of season over the eastern part of the United States. In a similar sense the dashed lines of figures 6-31 represent evaluations of rainfall-producing mechanisms at bi-weekly intervals. It is reasonable, then, to presume that the products of values for the same points on figures 6-31 (dashed lines) and on figure 35 should produce a reasonable picture of the seasonal variation of rainfall potential for 20,000 square miles and 72-hour duration. The solid lines in figures 6-31 were drawn from products of such values. They have been smoothed once through seasons and once for area at each season. Additional smoothings would result in minor changes in various portions of the charts but the generalized procedures followed in the development of the charts would belie the accuracy obtained by additional smoothings.

\section{DISCUSSION}

There were many interesting meteorological questions raised during the drawing of these charts: for example, the apparent short-lived period of intense rain of hurricane origin along the Middle Atlantic Coast, the influence of the Great Lakes on storms of large area and long duration, the northward migration of zones of intense rainfall during the spring, and what appears to be a double structure of areas of intense precipitation in May and June. Synoptic climatological studies of storms would very likely yield indications of the more direct causes of such variations. 


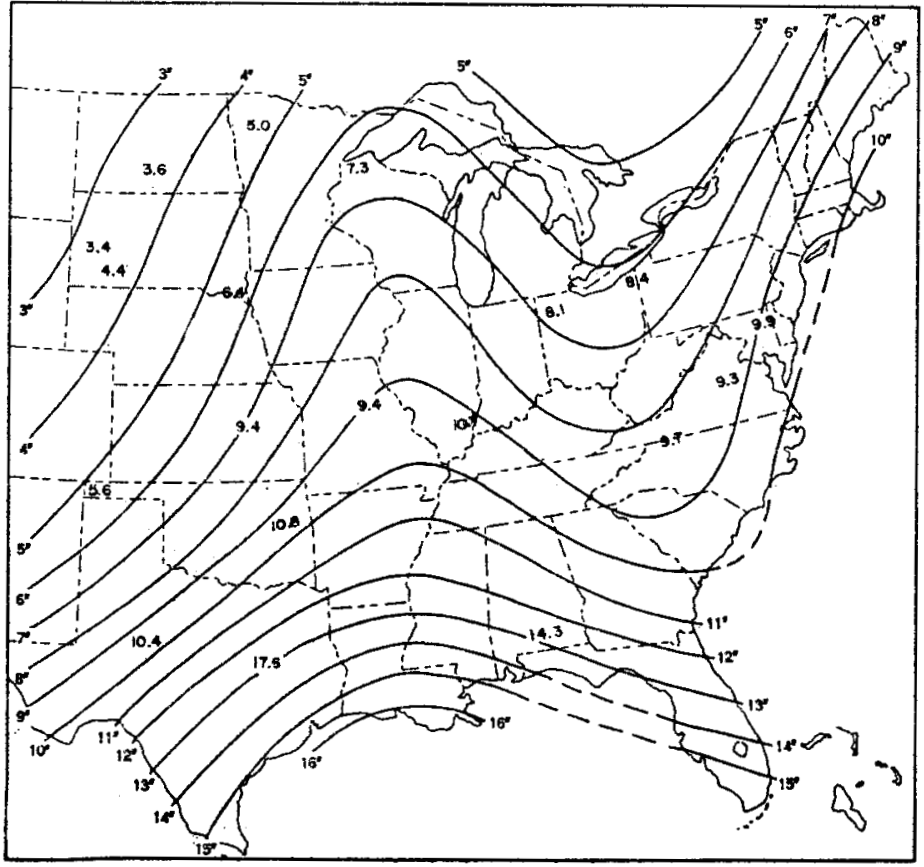

FraURe 35.-Depths of precipitation having approximately equal likelihood of occurrence; 20,000 sq. mi., 72 hours, all seasons. Plotted values show total rainfall amounts for storms which are undercut by the index.

For a number of years the Hydrometeorological Section has applied a technique of storm transposition to extend effectively the storm history of a particular area. On the basis of synoptic climatology limits are drawn delineating the area over which the apparent significant factors contributing to the mechanism of a particular rainstorm could reasonably occur. Areal transpositions of storms with suitable adjustments for moisture potential have been made in many studies, but temporal transpositions have arbitrarily been limited to 15 days. As an indication of adjustments required for either areal or temporal transposition of storms, or both, it appears reasonable to use the ratio of the index values at the time and place of occurrence to the values at the transposed time and location.

\section{ACKNOWLEDGMENTS}

The writer wishes to acknowledge the suggestions and criticisms of J. F. Appleby of the Hydrometeorological Section and D. E. Nunn of the Corps of Engineers who are currently analyzing seasonal variation of rainfall over small areas. Thanks are also due the sub-professional staff of the Hydrometeorological Section-A. E. Brown, A. L. Criss, J. L. Kiester, J. T. Lindgren, C. G. Ludwig, H. H. Vinnedge and F. C. Robrecht-who at various times assisted in the laborious task of plotting and tabulating the data, and to Miss M. I. Hammer for the typing.

\section{REFERENCES}

1. Corps of Engineers, Department of the Army, Storm Rainfall in the United States.

2. J. B. Kincer, Normal Weather for the United States, U. S. Weather Bureau, Washington D. C., 1943.

3. Stephen S. Visher, "Maps of Percentage Frequencies of Very Dry, Moderate and Very Wet Months," Monthly Weather Review, vol. 72, No. 3, March 1944, pp. 63-70.

4. W. F. McDonald, Average Precipitation in the United States for the Period 1906 to 1935 Inclusive, U. S. Weather Bureau, Washington, D. C., 1944.

5. Hydrometeorological Section, U. S. Weather Bureau Hydrometeorological Report No. 2, "Maximum Possible Precipitation, Ohio River Basin above Pittsburgh, Pa." In cooperation with the Corps of Engineers, War Department, Washington, June 1941.

6. Hydrometeorological Section, U. S. Weather Bureau, Hydrometeorological Report No. 29, "Seasonal Variation of the Standard Project Storm for Areas of 200 and 1000 Square Miles East of 105th Meridian," In cooperation with Corps of Engineers, Department of the Army, Washington, March 1953. 